\title{
Отражение речевой стихии времени в произведениях Михаила Зощенко
}

\author{
The living speech reflected in the works \\ of Mikhail Zoshchenko
}

\begin{abstract}
In his works Mikhail Zoshchenko presented a brilliant sense of the common language which developed in Russia after the revolution of 1917 , i.e. in a period of turbulent political changes and numerous social contradictions. The phenomenon of this writer is based on the constant interest of both readers and researchers in the specific language of his works. This is reflected in numerous statements by Zoshchenko's characters. In their responses, dialogues and monologues there are a number of orthoepic, spelling, grammatical, word-forming, semantic, stylistic and syntactic deficiencies. The deviations concern the principles of inflection, declination, generic belonging, an illogical and non-normative expression relationships. The issues above are analysed in the present article. In Zoshchenko's works, along with normative language, there coexist phenomena that are far from literary standards. His texts reflect the spoken language, which, like real communication, differs much from the normalized literary language. In order to show the spiritual and moral transformation of a man, Zoshchenko revealed and judged various distortions and defects in the post-revolutionary life of Russia. The writer chose for this short forms of narration - the short story, a tale, a sketch, a humoresque. The language of Zoshchenko's works is characterized by the crossing of various semantic and stylistic structures. In one context, inherently incompatible words and expressions are combined. This technique generates many semantic and stylistic shifts. In fact, Zoshchenko reflected the language that was spoken by many people in the post-revolutionary period. The writer tried to represent much of the speech of that time and use it humorously.
\end{abstract}

Keywords: Mikhail Zoshchenko, occasionalisms, alogisms, language deformations, non-normative syntax

Jarosław Wierzbiński, Uniwersytet Łódzki, Łódź - Polska, jaroslaw.wierzbinski@uni.lodz.pl, ORCID ID: https://orcid.org/0000-0002-1351-4276

Специфика зощенковского слога находит отражение в ряде трудов (см., напр.: Astaf'ev; Aulov; Žolnina; Isaeva; Kurošina; Lomova; Tomaševskij; Sinâvskij; Ruben; Serbakova; Âhiâeva; Zaharieva; Pyykkö; Drawicz; 
Jackiewicz; Kotkiewicz; Mucha; Wierzbiński). Этой проблематике посвящается также настоящая разработка, дополняющая имеющиеся в литературе сведения по вопросу словоупотребления в текстах писателя и развивающая отдельные положения о стилеобразующих факторах в его творчестве. В произведениях Михаила Зощенко рядом с нормативными фактами сосуществуют явления, которые далеки от литературных стандартов. Его тексты отражают разговорный язык, который, как и живое общение, отличается во многом от нормализованной и литературно складной, обработанной речи.

Язык художественных произведений Зощенко находится в тесной зависимости от эпохи, в которой писателю пришлось жить и заниматься литературной деятельностью. Словесная организация его текстов обусловлена, следовательно, рядом исторических предпосылок и других экстралингвистических факторов, существенных для послереволюционного периода.

После революции люди оказались в совершенно новых условиях. Сам писатель подчеркивал, что „Старой России нет... передо мной - новый мир, новые люди, новая речь” (цит. за: Eršov 6). Внутренняя ситуация России во многом осложнилась. Революция не преодолела общественных конфликтов, а социальные контрасты скорее усилились. Многие с трудом находили свое место, поскольку трудно было разобраться в новой обстановке. Зощенковский герой и повествователь - прямое свидетельство этих сложных исторических процессов.

В поисках духовного и нравственного перерождения человека Зощенко осуждал и обличал различные искривления и пороки в послереволюционной жизни России. Писатель избрал для этого краткую форму повествования - новеллу, рассказ, зарисовку, юмореску. В центре его рассказов оказывается преимущественно простой и малокультурный мещанин, обыкновенный „маленький” человек, который живет по-старому и еще не привык к тому, чтобы самостоятельно принимать решение и действовать. Мещанин того времени это

[...] злобствующий обыватель, согнанный с насиженной лежанки, думать не умел, трудиться не желал, в коммунизм не верил. Главной его задачей было - маскироваться и ждать [...]. Пройдохи разного калибра рядились в рабочие блузы, толкали революционные речи, старались войти в доверие к новой власти (Antonov 210).

Тот же мещанин старался всячески приспособиться к окружающей действительности. Зощенковский повествователь неоднократно также относится к мещанству пренебрежительно, о чем свидетельствует начало рассказа Мещзанство: 
О мещанстве Иван Петрович имел особое мнение. Он крайне резко и зло отзывался об этой накипи нэпа. Не любил он этой житейской плесени. - Для меня, - говорил Иван Петрович, - нету ничего хуже, как это мещанство. Потому через это вся дрянь в человеке обнаруживается... (Zoŝenko 287)1․

Общественно-политические преобразования повлекли за собой существенные изменения в отношениях между людьми, что привело к изменениям в области языка. Данное стремление нашло свое отражение также в речи зощенковских героев. В сочинениях писателя, кроме обиходных фраз, просторечных и областных слов, демонстрируются также различные деформации и отклонения от языкового регламента, которые прослеживаются на всех уровнях языка - фонологическом, морфемном, морфологическом, синтактическом, лексико-семантическом и стилистическом. Нелитературные лексические единицы и неправильные грамматические формы засвидетельствованы в следующих примерах:

(1) А теперича эта вредная гражданка меня в квартиру к себе не впущцает, [...] она, с перепугу, что ли, дверь поскорее хлопнула и руку мне прищемила по локоть. Я ору благим матом и кручусь перед дверью, а ихняя пудель заливается изнутре. Даже до слез обидно. $\mathrm{O}$ чем имею врачебную записку, и, окромя того, кровь и теперя текеть, если, например, ежедневно сдирать болячки (Zoŝenko 1: 162).

(2) Давеча в субботу после получки говорю ей запросто, как дорогой товарищ дорогому товарищу: - Приходите, говорю, Катюша, ко мне на квартиру. У печки, говорю, посидим. Фильму пойдем посмотрим. За вход заплачу (Zoŝenko 1: 287).

(3) - При царском режиме папаша торговали в Дерябинском рынке... Ну а теперича через эту nanamy мне форменная труба получается. Потому не приткнуться. Не берут в государственную службу (Zoŝenko 1: 252).

(4) - С чего бы, говорю, вам некогда? Какие, извините за сравнение, дела-то у вас? А парнишечка, дитя природы, отвечает басом: - Стареть начнешь, коли знать будешь много. Вот, думаю, какая парнишечка попалась (Zoŝenko 1: 297).

В приведенных примерах продемонстрированы различные отклонения от языковой нормы. В них нарушаются фонологические закономерности образования ряда словоформ. Часть словоформ в примере (1) принадлежит к просторечным образованиям. Ср. с этой точки зрения теперича и теперя вместо теперь; не впущзает вместо не впускает; окромя вместо кроме; кровь текеть вместо течет. Просторечная форма встречается также в примере

1 Данная цитата и в дальнейшем примеры приводятся с указанием на том и страницу по изданию: Зощенко 1986-1987 [Курсив в цитатах наш. - J.W.]. 
(2), ср. давеча в значении 'немного времени тому назад’. Во всех примерах (1), (2), (3), (4) обращают внимание отклонения от родовой нормы, что сказывается, естественно, и на звуковом оформлении слов или целых выражений. Существительное пудель в примере (1) отнесено к женскому роду, на что указывает родовая разновидность просторечной формы притяжательного местоимения ихняя. Нормативная модель сочетаемости требует в данном случае отнесенности к мужскому роду. В примере (2) родовая принадлежность существительного фильм тоже противоречит нормативной парадигме склонения. Неправильная и формулировка через эту папашу в примере (3), где наблюдается родовая некорректность. Ошибочная родовая отнесенность деминутивного деривата парнишечка определяет выбор в примере (4) словоформ какая и попалась вместо корректных форм мужского рода какой и попался. Нелишне отметить, что выражение извините за сравнение в этом примере лишено смысла, поскольку ставится вопрос, а сравнение как таковое отсутствует, так как ничто здесь не поддается никакому сравнению.

Об отклонениях от языковой нормы свидетельствуют выпадения звуков или вставки, редукция фонем и/или замена одних звуков другими, ср.:

(5) [...] сучка моя как заурчит, как прыгнет на старичка, как куснет его за левую руку, так он тут и скосился. Подбежали мы к старичку... [...] Так вот подошли мы к старичку. Позвали фершала. Фершал ранку осмотрел. - Да, говорит, это собачий укус небольшой сучки (Zoŝenko 1: 52).

(6) Вот с нашего двора Палька Ершов под режим экономии попал. Сократили парня. [...] - Палька, говорим, откройся, ослобони свою совесть. Чем ты, говорим, бродяга, кормишься? А он говорит: - Да знаете, ребятишки, я на другую службу поступил (Zoŝenko $1: 344)$.

(7) Мне вот случилась на днях работишка, вроде отхожий промысел, - не сумел воспользоваться. А промысел этот предложила девица одна. Кет - заглавие. Соседка. Рядом жили. [...] А раз утром девица встала и стучит кулаком в стену. - Эй, говорит, мон шер, не ли у вас спичек? [...] Я, говорю, хотя и безработный и питаюсь не ахти как, но говорю, спички есть. Взойдите (Zoŝenko 1: 252-253).

В этих контекстах звуковые просчеты самоочевидны, но, к тому же, они по-разному сказываются на смыслах слов. В примерах (5), (6) они не меняют узуальных значений, в то время как в примере (7) вместо войдите используется взойдите в данном значении, которое уже мало кем осознается ныне как устаревший и просторечный вариант для слова войдите. Лексема взойти семантизируется в современном русском языке следующим образом: 1. Идя, подняться куда-либо (взойти на гору); 2. Появиться, подняться над горизонтом (взошло солнце); 3. Разг. Вздуваясь, подняться (взошло те- 
сто); 4. Проросши, показаться над поверхностью почвы (семена взошли); 5. В значении войдите с указанными выше стилистическими пометами. В рассматриваемом примере (7) неуместное употребление слова заглавие, так как упоминается имя собственное девушки Кет. Нормативное употребление этой лексемы касается названия литературного, научного, музыкального произведения или его части (заглавие статьи, заглавие повести), но неуместно в случае имени.

Неизменяемые по падежам и числам слова в речи зощенковских персонажей неоднократно подвергаются изменениям. Несклоняемое существительное пальто приобретает падежные окончания как в единственном, так и во множественном числах, причем таким формам могут сопутствовать некоторые другие нарушения языкового узуса, ср.:

(8) Надеваю эти штаны, иду за пальтом. Пальто не выдают - номерок требуют. А номерок на ноге забытый. Раздеваться надо. Снял штаны, ищу номерок - нету номерка. [...] Веревка тут, на ноге, а бумажки нет. Смылась бумажка. Подаю банщику веревку - не хочет. - По веревке, говорит, не выдаю. Это, говорит, каждый гражданин настрижет веревок - польт не напасешься (Zoŝenko 1: 279).

В данном примере, кроме отмеченных грамматических форм существительного пальто, встречается несколько необычное сочетание настрижет веревок, вместо нарежет веревок. Стригут обычно ножницами волосы, настричь можно шерсти при стрижке овец.

Существительное кофе несклоняемое. Флективные изменения обнаруживаются для вариантов кофей и кофий, которые, однако, имеют устаревший и просторечный характер, ср.:

(9) - Ну, пойду, Машка, пойду, может, и выйдет что. Тут с телеграфиста начать надо. Телеграфист - главная запятая. - Не будь его, я бы, Машка, вчера еще с Домной Павловной кофей бы пил... (Zoŝenko 2: 20).

(10) А Авдотья Петровна выкушала два стакана кофея, кроме съеденных булок, и отвечает: - [...] делу может помочь единственное одно лицо. А это лицо - ужасно святой жизни старец Анисим (Zoŝenko 1: 209).

(11) Домна Павловна села рядом с Забежкиным. - Да это какой же, не помню чего-то? Это не тот ли - рыжеватый будто и угри на носу? - Тот, Домна Павловна. [...] - А я думала, он к Ивану Кириллычу прошел. Так ты бы его к столу пригласил. Сказал бы: вот, мол, Домна Павловна кофею просит выкушать... (Zoŝenko 2: 23-24).

Отклонения в области синтаксиса могут быть проиллюстрированы употреблением предлога в (во): 
(12) Он [врач - J.W.] послушал через трубку мое утомленное сердце и говорит: - Небось высоковато живете? В пятом или в шестом этаже? Эвон как сердце трепыхается. - Нет, говорю, живу во втором этаже (Zoŝenko 2: 440).

(13) [...] когда я вошел в помещение конторы, он [управдом - J.W.] выпрыгнул из окна, чтоб не беседовать по вопросам дома. Все жильцы, и я в том числе, сожалели, что кантора у нас находится не в седьмом этаже, а в первом. В силу чего наш управдом до сего времени здравствует и продолжает свой земной путь (Zoŝenko 2: 458).

Показательна в этом отношении также речь иностранца:

(14) Мы немного поговорим, и я вас сниму на память. Но что касается восьми часов, то в восемь часов, любезный коллега, мы уже идем в концерт. В восемь часов я никак не могу с вами встретиться (Zoŝenko 2: 408).

Слова у Зощенко обрастают непривычными смыслами или же подвергаются переосмыслению. Часто они лишаются своего словарного смысла. Взять, к примеру, функционирование термина аудиенция в следующей конситуации: обеспокоенный вопросами прохожего ночной сторож, карауливший магазин (он между двух закрытых дверей), выражает свое недовольство по этому поводу:

(15) - [...] Налил мне водички и иди себе с богом. Только мне спать мешаешь. Трещишь как сорока. Тут сторож допил свою воду, вытер рот рукавом и закрыл глаза, желая этим показать, что аудиенция закончена (Zoŝenko 2: 451).

Заимствованное слово аудиенция (от лат. audientia - слушание) по словарю обозначает официальный прием у лица, занимающего высокий государственный пост.

Иноязычная лексика, которой так охотно пользуется зощенковский повествователь, теряет свои смыслы. Такие слова часто применяются им в самых неожиданных контекстах и вопреки закрепленной за ними семантике. Они используются нередко также в извращенной форме. В качестве речевых средств в произведениях Зощенко вполне справедливо называется „прием обессмысливания иноязычных слов" (Pyykkö 123).

Среди речевых средств, к которым прибегает Зощенко, особую стилистическую активность обнаруживают выражения, соединяющие семантически несовместимые понятия. Создаются, таким образом, словесные единства, противоречащие устоявшимся связям слов, ср.:

(16) Одна симферопольская жительница, зубной врач О., вдова по происхождению, решила выйти замуж. Ну а замуж в настоящее время выйти не так просто! Тем более, если 
дама интеллигентная и ей охота видеть вокруг себя тоже интеллигентного, созвучного с ней субъекта! (Zoŝenko 3: 206).

Основное словарное значение лексемы происхождение касается принадлежности человека по рождению к какой-либо нации, классу, сословию. По рождению можно быть, к примеру, крестьянином, рабочим, а также русским, поляком, венгром и т. д. Обычно это слово определяет социальное происхождение, т. е. принадлежность людей к данным слоям в обществе, но никак оно не ассоциируется со статусом вдовы. Вдовой оказывается женщина после смерти мужа, а не от, предположим, классовой принадлежности. Фраза вдова по происхождению совершенно нелепа по смыслу.

(17) - [...] товарищ докторша, рубашку переменил, а другое, извиняюсь, не трогал. Вы, говорит, на них [ноги - J.W.] не обращайте внимания во время операции. Докторша, утомленная высшим образованием, говорит: - Ну, валяй скорей. Время дорого (Zoŝenko 1: 399).

Причина такой утомленности вызывает, по крайней мере, недоумение. Утомленным человек становится, скажем, от интенсивной деятельности, сопровождающейся большим напряжением, от усиленной умственной и/или физической работы. Испытывать усталость по поводу высшего образования, т. е. из-за совокупности знаний, полученных когда-то в результате обучения в мединституте - настоящий абсурд.

(18) В селе Усачи, Калужской губернии, на днях состоялись перевыборы председателя. [...] - Предлагается, - сказал городской товарищ, - выставить кандидатуру лиц. Михайло Бобров [...] сделал жест, приглашая немедленно выставить кандидатуру лии. Общество молчало (Zoŝenko 1: 273).

Между компонентами любого выражения должны соблюдаться семантико-грамматические отношения. В данном случае эти связи деформируются. Проявлением языковой нормы является синтаксическая структура выставить чью-нибудь кандидатуру, т. е. выдвинуть кого-то, предложить для обсуждения, для избрания куда-либо. За выражением выставить кандидатуру следует в узусе фамилия того, кто предполагается к избранию.

Показательны в речи зощенковских персонажей и такие смысловые и синтаксические ляпсусы:

(19) - Вот, Петя, какое дело. Я ушла с работы. [...] супруг чертовски взволновался. Ахает, кричит и просит. [...] Но супруга говорит: - Нет, довольно колбасы, я служить не буду. Я не имею намерения в душной канцелярии терять высокую квалификацию своей красоты и молодости (Zoŝenko 3: 246). 
(20) А кухонька, знаете, узкая. Драться неспособно. [...] - Уходи, Гаврилыч от греха. Гляди, последнюю ногу оборвут. Гаврилыч говорит: - Пущай, говорит, нога пропадает! А только, говорит, не могу я теперича уйти. Мне, говорит, сейчас всю амбицию в кровь разбили (Zoŝenko 1: 323).

Выделенные словесные конфигурации в примерах (19), (20) полностью извращают логичный ход рассуждений. Регламентированный способ выражения нарушает и такая конструкция:

(21) Ну, для формы спросишь - какая у тебя болезнь? Ну, больной сам, конечно, назвать болезнь не может и тем самым ставит врача в тупик [...]. Другие, конечно, говорят: Пиши, чего хочешь, только отпусти, поскольку душа болит - охота поглядеть на домашних. Ну, напишешь ему: душевная болезнь, и с этой диетой отпускаешь (Zoŝenko 2: 241).

Речь идет о распознавании болезни, о диагнозе, и это отождествляется с диетой, обозначающей соблюдение определенного режима питания при различных заболеваниях.

Разумным умозаключениям противоречит также следующая иллюстрация:

(22) Тут хотели за врачом побежать, но он не разрешил отнимать от дела рабочие руки. Но все-таки его отнесли домой, и там он под присмотром лучших врачей хворал в течение двух месяцев. Конечно, ему чудные похороны закатили. Музыка играла траурные вальсы (Zoŝenko 2: 339).

Сочетание траурные вальсы - оксюморонного типа, т. е. в нем соединяются слова, которые взаимно исключаются. На похоронах исполняется, как правило, траурный марш, а не вальс, музыка которого выдержана в ритме плавного танца и в радостных тонах. Траурных вальсов не бывает, в то время как марши могут быть веселыми и печальными, мрачными.

Очень выразительны и смысловые несоответствия лексических единиц, являющиеся результатом антонимической подмены, ср.:

(23) Среди, можно сказать, общего пешеходного тротуара - свинья мотается. Такая довольно крупная свинья, пудов, может быть, на семь. И пес ее знает, откуда она забрела. Но факт, что забрела и явно нарушает общественный беспорядок (Zoŝenko 1: 506).

(24) - Что вы, говорю, товарищ фельдшер, такие пошлые надписи вывешиваете? Все-таки, говорю, больным не доставляет интереса это читать. Фельдшер, или как там его лекпом, удивился, что я ему так сказал, и говорит: - Глядите: больной, и еле он ходит, и чуть у него пар изо рту не идет от жара, а также, говорит, наводит на все самокритику (Zoŝenko 2: 268). 
Нарушать можно общественный порядок, а наводить на все - критику. Выбор словоформ порядок и критику определяется семантико-грамматическими свойствами соответствующих глагольных форм: нарушать и наводить. В речи зощенковских персонажей такие нормативные связи между словами, однако, обрываются за счет введения антонимичных слов. Из приведенных контекстов (23), (24) следует: в первом случае - нарушается то, что уже само по себе является отсутствием или нарушением порядка; во втором же - получается, что больной критически относится к себе, вскрывает собственные ошибки, на самом деле герой критически относится к персоналу больницы, выявляя его недостатки по уходу за пациентами.

В ряде примеров прослеживаются случаи неуместной сочетаемости слов. Прилагательное интеллигентный употребляется обычно в сочетании с одушевленными существительными, напр.: интеллигентный ученик, человек и т. д. Между тем данное определение встречается в ином окружении:

(25) Покушал суп. Начал вареное мясо кушать - охота выпить. [...] - Эй, говорю, который тут мне порции подавал, неси мне, куриная твоя голова, лимонаду. Приносят, конечно, мне на интеллигентном подносе (Zoŝenko 1: 362-363).

Ср. также:

(26) И сам ученый агроном прищурил свои ученые глаза и велел мальчишкам отойти от тележки, чтобы видней было (Zoŝenko 2: 11).

Прилагательное ученые в нормативной речи не сочетается с существительным глаза. Оно обычно употребляется в случае характеристики многознающего человека. Поэтому стандартное употребление - это умные глаза. К тому же, из рассказа следует, что образованность агронома значительно преувеличена.

Небезынтересно употребление в речи зощенковских героев глаголов:

(27) И вот погрустил мужик до вечера. А вечером велит бабе своей, не жалея никаких денег, пригласить знаменитого Егорыча с Малой Охты. [...] Приглашает. Тот, конечно, покобенился. - Чего, говорит, я после знаменитых медиков туда и обратно ездить буду? Я человек без высшего образования, писать знаю плохо (Zoŝenko 1: 222).

Отмеченная сочетаемость глаголов противоречит грамматическим нормам.

Очередной алогизм основан на неправильном употреблении существительного пикничок. В словаре оно обозначает загородную прогулку с закуской, совершаемую компанией. В рассказе же данное существительное упо- 
требляется совсем неуместно, поскольку рассказчик называет этим словом поминки, ср.:

(28) Тут недавно маляр Иван Антонович Блохин скончался по болезни, а вдова его, средних лет дамочка, Марья Васильевна Блохина, на сороковой день небольшой пикничок устроила. И меня пригласила (Zoŝenko 1: 305).

Несопоставимость слов оксюморонного характера прослеживается в следующем примере:

(29) Пришел Андрон. Выговорил себе цену, попросил карандаш, сам сбегал за бумагой и стал писать. Час или два писал, вспотел, но написал: „Я здоров, и папаша покойный здоров во имя отца и святого духа. Дворник дома № 6. Андрон” (Zoŝenko 1: 223).

Значения рядом стоящих слов (покойный здоров) исключают друг друга, их употребление указывает на нелепость ситуации, в которой оказались герои рассказа.

От любого текста ожидается, как правило, движение содержания, его развертывание, т. е. тема-рематическая прогрессия очередных сегментов. Слова в речевом потоке должны объединяться по смыслу. Коммуникативная последовательность высказываний нуждается также в соблюдении грамматических, логических, стилистических связей. Между тем, зощенковский герой достаточно регулярно объединяет слова произвольно, нарушая или полностью обрывая связи между единицами текста. Примером может послужить следующий фрагмент обращения чиновника к женщинам за их раскрепощение:

(30) - Гражданки! Вы, которые эти белые рабыни плиты и тому подобное. И которые деспот муж элемент несознательно относится. И кухня, которая эта и тому подобное. Шитье, одним словом. Довольно этих про этих цепей. Полное раскрепощение, к свету нога об руку с наукой и техникой (Zoŝenko 1: 267).

Из примеров явствует, что в зощенковских текстах весьма часты случаи нарушения регламентированного способа выражения. Отступления от языкового узуса многоаспектны. Различные языковые деформации предопределяют особую сатирическую тональность текстов писателя. Они обнаруживаются в авторской речи, но отражены преимущественно в языке представителей различных социальных слоев. В речи его персонажей нарушается родовая отнесенность слов, не соблюдается языковое согласование или звучат неправильные грамматические формы, о чем свидетельствуют и такие примеры: 
(31) $[. .$.$] напяливаю кепку на нос, покупаю сигару и ее закуриваю и вот в таком неес-$ тественном виде со своим экспортным чемоданом вламываюсь снова в эту гостиницу. Швейцар говорит: - Напрасно будете заходить - номерей нету (Zoŝenko 3: 325).

(32) Весовщик говорит: - Стыдно! Здесь взяток не берут. [...] обратитесь вот до того рабочего: он вам укрепит слабую тару. А что касается денег, то благодарите судьбу, что у меня мало времени возжаться с вами (Zoŝenko 3: 310).

(33) Гляжу, один гражданин в трех шайках моется. В одной стоит, в другой башку мылит. А третью левой рукой придерживает, чтоб не сперли. Потянул я третью шайку, хотел, между прочим, ее себе взять, а гражданин не выпyщ̨ает (Zoŝenko 1: 278).

Итак, язык зощенковских текстов далек от литературных стандартов. В нем наблюдается постоянное нарушение закономерностей литературной речи. Отметим попутно, что примеры деформирования речи в целом направляют анализ не только в сторону безобидного пародирования неуклюжих выражений, что они воспроизводятся не только ради смеха. В них отчетливо проявляется социологическая наблюдательность писателя, разоблачающего различные отрицательные явления языковой действительности.

Писателя неоднократно упрекали в том, что его язык предстает в искаженном виде, что речь впадает в карикатуру. Критика негодовала по поводу словесного оформления его текстов, нарушения логических связей и традиционных принципов построения фраз. Эти „искажения”, по всей вероятности, лишь отчасти можно отнести к языковой игре. В этом плане показательны высказывания самого Зощенко, который не соглашается с критическими замечаниями редактора журнала „Современник”:

[...] Ваши рассказы очень талантливы... Но согласитесь сами - это немножко шарж. Это не шарж, - говорю я. - Ну, взять хотя бы язык... - Язык не шаржирован. Это синтаксис улицы... народа. Быть может, я немного утрировал, чтоб это было сатирично, чтоб это критиковало... (Zoŝenko 3: 507).

Язык произведений Зощенко характеризуется скрещиванием различных семантико-стилистических структур. В одном контексте совмещаются по существу несовместимые слова и выражения. Данный прием порождает ряд смысловых и стилистических сдвигов. Столкновение разных речевых структур приводит к особым трансформациям словарных смыслов. Наблюдается усложнение семантической структуры общеизвестной и зачастую нейтральной в словарном отношении лексики, приобретающей в определенной конситуации неожиданные смысловые акценты, дополнительные коннотации (в том числе эмотивные и экспрессивные). 
Формирование дополнительных оттенков смысла обнаруживается при окказиональном употреблении лексем, которое осуществляется в определенном лингвистическом и ситуативном окружении. Заданные смысловые приращения возникают на базе оформления текста как сложного структурно-семантического целого, они проецируются по мере его движения.

Итак, язык зощенковских текстов не подражает литературной речи. Он не приспосабливается к трафаретным образцам, а характеризуется нарушениями в области флективных парадигм и грамматической категории рода, отсутствием - в ряде случаев - логической последовательности и формальной гармонии между единицами текста, наличием необычных смысловых оттенков и переосмыслением слов. Ему свойственны особые сочетания и синтаксические построения, доведенные, иной раз, до абсурда. Критика не щадила в свое время писателя по поводу передачи столь деформированной речи. В действительности же Зощенко типизировал тот язык, на котором говорили широкие слои населения в послереволюционный период. Писатель „стремился зафиксировать многое из речевой стихии времени и комически это использовать” (Pyykkö 122). Произведения Зощенко являются в этом отношении богатейшим воплощением языковой действительности во всем ее многообразии.

\section{Библиография}

Âhiâeva, Saidat Hizbulaevna. „Rol'i funkciâ «govorâsih» familij v proizvedeniâh M. Zoŝenko”. Vestnik Dagestanskogo gosudarstvennogo universiteta, 4, 2014, s. 305-313.

Antonov, Sergej. „M. Zoŝenko. Stanovlenie stilâ”. Literaturnaâ učeba, 6, 1984, s. 203-213.

Astaf'ev, Andrej. „Okkazionalizmy v rasskazah M. M. Zoŝenko”. Russkaâ reč', 4, 2012, s. 25-26.

Aulov, Anatolij Mihajlovič. Rasskazy M. Zoŝenko 20-h godov. Problema žanra i stilâ: avtoref. dis. kand. filol. nauk. Moskva, 1998.

Drawicz, Andrzej. „Moralista z powołania, humorysta mimo woli”. M. Zoszczenko. Punkt widzenia. Opowiadania i powieści. Warszawa, Czytelnik, 1985, s. 529-540.

Eršov, Leonid Fedorovič. Iz istorii sovetskoj satiry. M. Zoŝenko i satiričeskaâ proza 20-40-h godov. Leningrad, Nauka, 1973.

Isaeva, Larisa Abdurahmanovna. Kommunikativnyj i konnotativnyj aspekty knižnyh leksičeskih i frazeologičeskih edinic $v$ hudožestvennyh tekstah (na materiale rasskazov M.M.Zoŝenko). Nazran', Izdatel'stvo Kep, 2012.

Jackiewicz, Mieczysław. „Elementy groteski w krótkich opowiadaniach Michaiła Zoszczenki”. Małe formy w literaturze rosyjskiej. Stowo w tekście rosyjskim. Literaturoznawstwo. Olsztyn, Wydawnictwa Wyższej Szkoły Pedagogicznej, 1991, s. 97-105.

Kotkiewicz, Aurelia. Nowy czlowiek Michaiła Zoszczenki. Trylogia: „Przywrócona młodość”, „Niebieska księga”, „Przed wschodem słońca”. Kraków, Wydawnictwo Naukowe Uniwersytetu Pedagogicznego, 2012.

Kurošina, Zoâ Vladimirovna. „Problema čistoty russkogo âzyka v rasskaze M. Zoŝenko «Obez'ânin âzyk»”. Russkij âzyk v škole, 4, 2009, s. 43-46. 
Lomova, Tat'âna Mihajlovna. „Četyre uroka u Zoŝenko”. Literatura v škole, 7, 2013, s. 19-20.

Mucha, Wacław. Opowiadania satyryczne i humorystyczne Michaiła Zoszczenki (1921-1932). Z zagadnień poetyki i komunikacji literackiej. Wrocław-Warszawa-Kraków-Gdańsk-Łódź, Wydawnictwo Polskiej Akademii Nauk, 1985.

Pyykkö, Riitta. „Otraženie leksičeskih izmenenij poslerevolûcionnogo perioda v rasskazah Mihaila Zoŝenko". Studia Slavica Finlandensia, 10, 1993, s. 119-131.

Ruben, Berngard Savel'evič. Alibi Mihaila Zoŝenko. Moskva, Izdatel'stvo Agraf, 2001.

Ŝerbakova, Polina Olegovna. „Soznanie «massovogo geroâ» i formy ego vyraženiâ v cikle M. Zoŝenko «Rasskazy Nazara Il'iča Gospodina Sinebrûhova»". Vestnik Voronežskogo gosudarstvennogo universiteta. Seriâ Filologiâ. Žurnalistika, 1, 2013, s. 119-123.

Sinâvskij, Andrej. „Mify Mihaila Zoŝenko”. Voprosy literatury, 2, 1989, s. 50-67.

Tomaševskij, Ûrij Vladimirovič. „Pâtnadcat' minut iz žizni Muzy”. Stolica, 8, 1992, s. 61-62.

Vežbin'ski, Âroslav. „Inoâzyčnye vkrapleniâ v russkoj hudožestvennoj literature (na materiale proizvedenij Mihaila Zoŝenko)". Beiträge zur Slavistik. Band 27: Innerslavischer und slavischdeutscher Sprachvergleich. Red. Herbert Jelitte, Tat'âna Troškina. Frankfurt am Main-BerlinBern-New York-Paris-Wien, Peter Lang, 1995, s. 241-253.

Wierzbiński, Jarosław. „Illûziâ inostrannoj reči v strukture tekstov Mihaila Zoŝenko”. Studia Rossica Posnaniensia, 43, 2018, s. 315-326.

Zaharieva, Irina. „Rasskazy Mihaila Zoŝenko”. Bolgarskâ̂ rusistika, 1, 1989, s. 9-19.

Žolnina, Elena Vladimirovna. „,Golubaâ kniga” M.M. Zoŝenko: tekst i kontekst: avtoref. dis. kand. filol. nauk. Sankt-Peterburg, 2007.

Zoŝenko, Mihail. Sobranie sočinenij v treh tomah. Leningrad, Hudožestvennaâ literatura, 19861987. 